REVISTA ECONOMÍA

Vol. 68, N. ${ }^{\circ}$ IO7 (mayo 20I6), I37-I5I

\title{
EL INSTITUTO NACIONAL DE INVESTIGACIONES AGROPECUARIAS \\ Y LA MODERNIZACIÓN AGRARIA EN ECUADOR
}

\author{
ANTONIO CHAMORRO \\ Flacso-Ecuador
}

Recepción manuscrito: 15 de marzo de 2016

Aceptación versión final: 29 de abril de 2016

\begin{abstract}
RESUMEN La investigación es un estudio del proceso de transferencia tecnológica realizado por el INIAP de Ecuador desde 1964 hasta el año 1994. El inicio corresponde a la primera Ley de Reforma Agraria impuesta por decreto por la Junta Militar, y el final a la Ley de Desarrollo Agropecuario, implementada por el gobierno del presidente Sixto Durán Ballén, y que puede considerarse como el final de un proceso que revertirá la reforma iniciada en 1964.
\end{abstract}

PALABRAS CLAVE Modernización agraria, revolución verde, transferencia tecnológica, construcción social de la tecnología.

\begin{abstract}
This research is a study of the technological transfer process done by INIAP in Ecuador from 1964 to 1994. The start corresponds to the first Agricultural Reform Law imposed by decree of the Military Junta, and the end, to the Agricultural-and-Livestock Development Law, implemented by the government of President Sixto Duran Ballen, and which can be considered as the end of a process that will reverse the reform started in 1964.

KEYWORDS Agricultural modernization, green revolution, technological transfer, technological social construction
\end{abstract}

JEL CODE Q18.

\section{INTRODUCCIÓN: MODERNIZACIÓN AGRARIA}

La agricultura ha ocupado un papel central en el proyecto de modernización capitalista (Moore, 2010, p. 389), las formas capitalistas de producción y consumo surgieron primero en la agricultura, el mercado mundial de alimentos fue y continúa siendo central para el desarrollo del capitalismo a nivel global (McMichael 2000, p. 128). El modelo agrícola basado en la ciencia fue una invención del siglo xx (Borlaug, 2000, p. 2); este modelo tiene su origen en el desarrollo tecnológico y en la necesidad de desarrollar una agricultura que sintonizase con las economías de escala que permitiese abastecer a los mercados internacionales (Altieri y Nicolls, 2010, p. 2). El patrón para su desarrollo fue la difusión de las tecnologías de las innovaciones estadounidenses al resto del mundo. Este proceso se vincula con el surgimiento de las teorías del desarrollo. El objetivo era el crecimiento, el agente del desarrollo fue el Estado y los instrumentos 
las políticas macroeconómicas (Leys, 1996, p. 7). Después de la Segunda Guerra Mundial se produjo el quiebre colonial y la guerra fría. Los estudios agrarios se expandieron por América Latina en un momento en que las ciencias sociales estaban muy influidas por el marxismo y los estudios de la dependencia, sin embargo, en el campo de la economía predominaron las teorías estructuralistas (Kay, 2008, p. 916). En este contexto surge en los años 1950 la «teoría del desarrollo» con el objetivo de entender de qué modo las economías de las colonias podrían ser transformadas para hacerlas más productivas conforme avanzaba la descolonización, o la todavía condición semicolonial de algunos países en Latinoamérica (Leys, 1996, p. 5).

Los procesos de desarrollo agrario al interior de Estados Unidos y la necesidad de exportar un modelo altamente tecnológico hacía que fuera preciso modernizar los sistemas agrarios de estos países. La política agraria modernizadora se centró en aumentar la productividad de la tierra mediante la introducción de una solución tecnológica bajo la forma del paquete tecnológico de la Revolución Verde (Parayil, 2003, pp. 975-976). Este modelo fue implementado a nivel internacional a través de sistemas de investigación agraria nacionales que se enfocaron en el desarrollo de variedades de semillas altamente productivas que serían adaptadas a las condiciones locales de cada país, de este modo la agricultura fue manejada en base a un modelo a escala y generalista, concediendo un valor marginal a la condiciones locales. Destaca en este periodo el proyecto modernizador de Rostow, dirigido a cambiar las estructuras tradicionales a partir de fuerzas externas para adaptarlas a las necesidades de un crecimiento sostenido (Rostow, 1961, p. 40). Las sociedades latinoamericanas eran consideradas herederas de modos tradicionales de producción a pesar de su mestizaje europeo. La agricultura latinoamericana empleaba el $75 \%$ de la fuerza laboral, por lo que precisaba de la introducción de cambios que permitiesen el desarrollo de la industria (Rostow, 1961, p. 42). Para lograrlo la naturaleza será entendida como un mundo ordenado al que habrá que acercarse de forma racional para que contribuya al progreso (Rostow, 1961, p. 42). Esta concepción de la agricultura como algo mecánico que es posible diseñar y controlar, donde el agricultor es un receptor de tecnologías, subyace en el modelo agrario que será desarrollado y difundido a través de los institutos de investigación agraria.

La modernización debe ser entendida en relación al proceso por el que el capital «se desplaza» continuamente hacia nuevas industrias y líneas de producción, en busca de beneficios más elevados y un control mayor sobre la fuerza de trabajo (Silver, 2005, p. 89). El desarrollo agrario representaba un nuevo campo para el capitalismo, a la vez que permitía generar un orden político estable en las antiguas colonias. Por tanto, los procesos de modernización no pueden desvincularse del modo en que el capital ha reorganizado los acuerdos sociales y técnicos que articulan las granjas a nivel global (Akram-Lodhi y Kay, 2010, p. 178).

\section{REVOLUCIÓN VERDE}

La Revolución Verde se refiere a un proyecto de transferencia tecnológica durante la era poscolonial, y es en gran medida el producto de la innovación tecnológica en el dominio público (Parayil 2003, p. 974), donde la ciencia y la tecnología estuvieron orientadas a mejorar la cantidad, calidad y la disponibilidad de alimentos para la población mundial (Borlaug, 2000, p. 1). La exportación de soluciones tecnológicas después de la Segunda Guerra Mundial a través del 
paquete tecnológico de la revolución verde supuso la institucionalización de la tecnología para solucionar el problema del hambre, mediante un proceso de transferencia tecnológica organizado por el Estado e influenciado por diversas agencias internacionales. Esta estrategia transformó la vida de millones de personas y fue considerado el proyecto más exitoso desde el Plan Marshall y la reconstrucción de Europa después de la Segunda Guerra Mundial (Wolf, 1986, p. 6).

Su comienzo se sitúa en 1954, los precursores pueden encontrarse en el espectacular incremento de la productividad de semillas de maíz híbrido experimentado por los granjeros de Estados Unidos en la década 1930-1940, y en los años 40 en México gracias al esfuerzo de la Fundación Rockefeller para aumentar la productividad del trigo y el maíz (Klopppenburg, 1988). La revolución verde significó un hito para la agricultura internacional, la introducción de nuevas variedades de semillas vino acompañada del uso de maquinaria agrícola, así como de fertilizantes y pesticidas de síntesis química, permitiendo el aumento de la producción de alimentos (Wolf, 1986, p. 1). Sin embargo, su distribución, el acceso a los insumos y créditos fue desigual (Wolf, 1986, p. 6).

\section{MARCO CONCEPTUAL}

La revolución verde ocurre en un contexto en el que hay un conocimiento agrícola previo que será cuestionado por la introducción de un nuevo modelo modernizador. La generación del conocimiento científico es el resultado de las interacciones entre diversos actores que operan dentro de campos de conocimiento heterogéneos (Callon, 2013, p. 107), donde los posicionamientos que ocurren para acceder a diferentes formas de capital son esenciales, pues estas disputas ordenan las representaciones reales del espacio social y las tomas de posición que surgen a su alrededor (Bourdieu, 1997, p. 25). Los procesos modernizadores no discurren sobre una tabula rasa, sino sobre la base de marcos conceptuales y procedimientos preexistentes. La construcción del conocimiento es el resultado de la convergencia de un gran número de decisiones y de la incorporación selectiva de ideas previas, creencias e imágenes, al mismo tiempo que destruye otros marcos de conceptualización y comprensión (Arce y Long, 1992, p. 211). Estos procesos no son ajenos a los procesos de poder, autoridad y legitimidad en que están insertos los diferentes actores implicados (Arce y Long, 1992, p. 214).

Los espacios sociales son espacios en movimiento donde se generan lugares de convergencia y de diferencia, en el sentido de tomas de posición para acceder a diferentes formas de capital (Bourdieu, 1997, p. 28). Esto produce diferencias, en el sentido de rasgos distintivos (Bourdieu, 1997, p. 16), favoreciendo determinadas preferencias frente a otras, como un modelo agrario adaptado a explotaciones de monocultivos de tamaño medio y grande orientado al mercado, que precisa de una determinada tecnología frente a un modelo orientado al pequeño que precisa de un enfoque agrario más integral.

\section{LA TRANSFERENCIA TECNOLÓGICA Y LA REVOLUCIÓN VERDE}

La introducción de una nueva tecnología tiene normalmente un efecto disruptivo, especialmente sobre la sociedad primitiva. Las adaptaciones tecnológicas son de dos tipos, una es social y otra técnica (Layton, 1987, p. 152). Los cambios tecnológicos fueron desarrollados en el periodo posterior a las guerras mundiales y durante el proceso descolonizador, esto invita a 
reflexionar en qué medida tanto el contexto como el ser humano fueron redefinidos por estos procesos (Latour, 2007, p. 20). La transferencia tecnológica y la adaptación local del trabajo ocurridas durante la revolución verde fueron promovidas desde el dominio público para buscar soluciones tecnológicas que permitiesen aumentar la productividad agrícola y vencer las limitaciones naturales. En este sentido, resulta crucial analizar el proceso de transferencia tecnológica realizado desde el INIAP, pero integrando en el análisis un contexto socio-técnico y político más amplio (Pinch, Ashmore y Mulkay,1992, p. 273).

El enfoque de la Construcción Social de la Tecnología (CST), desarrollado a comienzos de los años 80 por Bijker y Pinch, considera que el cambio tecnológico está determinado en mayor medida por procesos sociales más que por cualquier «lógica tecnológica» interna (Bruun y Hunniker, 2013, pp. 194-195). La forma de los contenidos y los argumentos sobre la tecnología están influidos por la esfera social, esto implica que un enfoque relativista empuja a un relativismo en relación a los intereses sociales, es decir, a una neutralidad política (Steward, 1986, pp. 332-333). Aunque el problema tecnológico es construido por un grupo social relevante, que comparte una serie de significados y considera qué es un "problema» (Bijker y Pinch, 1987, p. 30). Sin embargo, pensar que los procesos de transferencia se deciden solo a este nivel, pierde de vista la complejidad de las negociaciones que tienen lugar sobre el terreno. Pues la ciencia y la tecnología no son estructuras aisladas y monolíticas, sino procesos fermentados socialmente en una variedad de circunstancias distintas (Bijker y Pinch, 2013, p. 25), donde los sistemas tecnológicos forman parte de constelaciones sociales y están integrados en redes de relaciones que configuran la sociedad (Hughes, 2013, p. 101). Por lo que es preciso integrar las conexiones que se establecen a su alrededor (Latour, 2005, p. 14), para entender de qué modo las revoluciones tecnológicas están vinculadas a las revoluciones sociales y políticas (Sweezy, 1972, p. 25).

Desde este enfoque teórico se abordan las visiones de los diversos actores involucrados en los procesos de cambio tecnológico surgidos alrededor del InIAP, de modo que se pueda obtener una visión integral del proceso de difusión tecnológica y su interrelación con la sociedad (Bijker y Pinch, 2013, p. 25). Para poder visualizar cómo se construye el conocimiento dentro de una comunidad de científicos como la del INIAP, y las negociaciones que surgen entre los diferentes actores, así como las implicaciones de un determinado marco de pensamiento y de una coyuntura social e institucional en el desarrollo de un determinado modelo agrario. La metodología empleada ha sido el análisis de los informes anuales del INIAP entre los años 1963 y 1973, de los archivos del programa de Palma entre 1971-1983, de los informes del Programa de Investigación en Producción (PIP) y del programa de cultivos andinos. Así como la realización de entrevistas con personas clave relacionadas con el INIAP, el Ministerio de Agricultura y actores relevantes de la sociedad civil.

\section{EL INIAP}

El INIAP fue creado, como el resto de institutos de investigación agraria que poblaron el continente, para difundir un determinado modelo agrario. Su historia tiene particularidades que permiten entender cómo ha sido el proceso modernizador en el país. Por allí pasaron investigadores extranjeros, mientras que los investigadores nacionales viajaban a otras latitudes 
para absorber el conocimiento agrario moderno, tejiendo una red de investigación con instituciones internacionales. La investigación agraria se articuló alrededor de centros y periferias, según una determinada hoja de ruta. En los centros de investigación internacionales se generó un flujo de conocimiento científico-técnico encaminado a fortalecer un modelo basado en el uso de variedades mejoradas, fertilización química, pesticidas de síntesis química y el empleo de maquinaria pesada. Este modelo sería diseminado por técnicos formados en los institutos de investigación, que operaron como centros de validación y adaptación a nivel local de un modelo agrario que no respondía a los intereses nacionales, sino a los de generar un empresario agrícola. De este modo, durante las primeras décadas del INIAP se produjo una simbiosis entre el capital público y el privado, que permitió el trasvase de la investigación hacia el sector privado.

Entre los institutos y centros que colaboraron con el INIAP cabe destacar el Instituto para la Investigación de Aceites y Oleaginosas (IRHO), de Francia, que desempeñó un papel crucial en el desarrollo de la palma africana. El gobierno holandés fue central en el desarrollo de la ganadería lechera. El Centro Internacional para el Mejoramiento del Maíz y el Trigo (Сіммүт), fundado al igual que el INIAP por la Fundación Rockefeller, proveyó a la institución de variedades de cereales. El Centro Internacional de la Papa (CIP) se ocupó de la investigación en papas. Cada uno de estos centros se formó para trabajar con un cultivo específico desde criterios técnicos que permitiesen aumentar la productividad.

\section{PRIMERAS ESTACIONES EXPERIMENTALES: 1943}

Si antes de 1940 Estados Unidos no daba prioridad a los asuntos internacionales (Ortega Aranda 1966, p. 5), a raíz de la Segunda Guerra Mundial, y después con la Alianza para el Progreso, la política internacional irá adquiriendo una relevancia mayor. La creación del INIAP estuvo precedida por la fundación de la estación de Pichilingue en 1943 (Robles, 2011, p. 4), creada durante la Segunda Guerra Mundial junto con otras estaciones en Centroamérica y Sudamérica para producir caucho y fibra destinados a la elaboración uniformes, pues los japoneses habían invadido los países del sudeste asiático acaparando las reservas de caucho.

\section{COLABORACIÓN EXTRANJERA Y EMPRESA PRIVADA: 1963-1978}

Su fundación no respondía solo a necesidades productivas, pues con la población que tenía el país en esa época era sustentable a nivel alimenticio. El motivo principal habría que situarlo en su rol dentro de la estrategia de implementación de un modelo de desarrollo de la industria, que según la Doctrina Truman tendría como ejes centrales la creación de sociedades modernas y urbanas (Escobar, 2007, pp. 19-20). El objetivo era eliminar el lastre de las relaciones feudales para permitir el desenvolvimiento del sector empresarial (Martínez, 1983, p. 39) y seguir el modelo de industrialización inspirado por la Comisión Económica para América Latina y el Caribe (CEPAL) que garantizase que se produjesen suficientes alimentos con menos mano de obra, fortalecer el sector agroexportador y mejorar las vías de transporte.

La estrategia de formación del INIAP responderá por tanto a este modelo, su fundación en 1959 contó con el apoyo de la financiación extranjera, en especial de la Fundación Rockefeller y del Banco Interamericano de Desarrollo (BID). El trabajo del INIAP comenzó en 1962 con un 
grupo de investigadores, el objetivo era realizar investigaciones en productos destinados a la canasta familiar y a la exportación (Robles, 2011, p. 6). Su creación coincide con la construcción del Estado ecuatoriano en 1954, que se verá debilitado por los sucesivos golpes militares y la continua problemática política. El hecho de que el Estado no termine de fortalecerse a lo largo de la segunda mitad del siglo xx, le marcará indeleblemente. En este primer periodo que podemos situar hasta 1975 se sucedieron los convenios de asistencia técnica y los proyectos de investigación, la colaboración extranjera fue intensa, se crearon cuadros técnicos que ayudaron a sentar las bases de la investigación en el país, se formó a muchos técnicos que después de egresar de las universidades nacionales siguieron estudios de posgrado en universidades extranjeras gracias al apoyo financiero de la fundación Rockefeller y del BID.

En esta época el instituto tuvo una relación fluida con la empresa privada, la junta directiva estaba formada por sectores privados, donde muchos eran antiguos hacendados que se modernizaron para adaptarse al momento actual. Destaca el trabajo y la visión del primer director del INIAP, el ingeniero Fabián Portilla, su operatividad con gran independencia del poder político nacional, su liderazgo y sus buenas relaciones con la Fundación Rockefeller, favorecieron la captación de recursos económicos para la institución, aspectos que permitieron la formación de un instituto con sólidos cimientos y que logró alcanzar una buena imagen y reconocimiento internacional. Su salida forzada por la junta militar en 1974 será un duro golpe para la institución.

\section{LA MISIÓN HOLANDESA Y LA INICIATIVA TERRATENIENTE: GANADERÍA LECHERA}

Esta época corresponde a la consolidación de lo que Cosse (1980) denominó la iniciativa terrateniente, un movimiento defensivo que respondía a sus intereses económicos (Murmis,198o, p. 21). También hay una identificación de zonas potenciales donde se asentarán empresas rentables como la palma africana y la ganadería lechera. En la Sierra, la reforma fomentada por Galo Plaza, un agricultor terrateniente serrano favorable a la modernización que contaba con el apoyo de los liberales, y que estaba conectado con los Estados Unidos y con las compañías extranjeras (Cosse, 1980, p. 397), buscaba fragmentar la hacienda para acabar con las relaciones de servidumbre, pues no obedecían al capitalismo moderno. La idea esencial era generar ciertos cambios antes de que las movilizaciones sociales hicieran peligrar el sistema en su conjunto (Barsky, 1988, p. 61). La entrega de tierra calmó inicialmente las tensiones sociales; sin embargo, sus efectos se dejaron notar más en la Sierra que en la Costa, donde en los años 70 hubo revueltas sociales. La fuerte represión del movimiento obrero alcanzó su máxima expresión en 1977 durante la masacre de los trabajadores del sector azucarero en Aztra (Cueva, 2003, p. 84).

El modelo modernizador del Estado ecuatoriano auspiciado por Galo Plaza favoreció el que se desarrollasen algunas instituciones fuertes. La iniciativa terrateniente motivó la transformación de algunas haciendas en empresas ganaderas y la eliminación de las relaciones precarias (Barsky, 1988, p. 65). El programa de ganadería lechera ha sido considerado exitoso por algunos de los técnicos del INIAP entrevistados, señalándolo como uno de los mejores proyectos, permitiendo incluso que la investigación desarrollada llegase a los pequeños agricultores, aunque sin duda fueron los hacendados modernizadores los que más se beneficiaron de estos programas, que pudieron poner en práctica en sus tierras. Este programa fue posible gracias 
a un acuerdo firmado en 1965 entre el gobierno ecuatoriano y el holandés, conocido como la Misión Holandesa. Ecuador no producía mucha leche, los holandeses trajeron tecnología avanzada y hubo una colaboración muy enriquecedora entre ambas partes. Se trajeron nuevas variedades de ganado Holstein-Friesland que lograron adaptar a las condiciones locales por cruzamiento y retrocruzamiento con variedades locales, siendo la altura el factor más limitante. Además se desarrollaron pastos, lo que permitió mejorar progresivamente la alimentación de los animales y aumentar su resistencia, hubo un buen manejo de plagas y se mejoró la fertilidad del suelo con abonos verdes. También se capacitó al personal que hacía las labores de mayordomeo mediante la apertura de una escuela al interior de Santa Catalina, donde se impartieron cursos intensivos que duraban seis meses.

La Misión Holandesa favoreció la comunicación con la comunidad productora mediante la organización de días de campo y hubo cierta convergencia entre la investigación, la difusión y la capacitación de mayordomos en el manejo del ganado. Destaca también la interacción con la empresa privada lo que permitió generar una industria ganadera en el país y satisfacer las necesidades de los grandes hacendados, que veían en el desarrollo de la ganadería lechera un gran potencial. El éxito de la ganadería lechera se debe a que la finca se puede manejar con poca gente, mientras que cultivos como la papa exigían más mano de obra, lo que podía generar problemas por las nuevas leyes de la reforma agraria. Con la reforma se liberaba a la población sujeta a relaciones de servidumbre de la dependencia a la que había sido históricamente sometida. La ganadería permitía sacar gente y trabajar con pocos trabajadores; en este sentido la inversión unida a la elección de los sectores modernizadores (Murmis, 1980, p. 22) propició determinadas medidas políticas que orientaron el modelo agrario a sus intereses.

\section{NUEVOS CULTIVOS DE COLONIZACIÓN: PALMA AFRICANA}

La palma fue introducida en 1953 en Santo Domingo de los Colorados (hoy Tsácilas), para fomentar su cultivo se creó en 1961 el Programa de Palma Africana de la Dirección General de Agricultura del Ministerio de Fomento con préstamos y el asesoramiento del BID (INIAP, 1979, p. 75). En 1963 el BID y la Comisión Nacional de Valores estimaron que era más conveniente que el programa pasase al INIAP (INIAP, 1979, 75). Su expansión se vio favorecida por el Primer Plan Piloto impuesto por decreto de la Junta Militar en 1964 (Carrión y Cuvi, 1985, p. 31). La palma entraba directamente como un cultivo capitalista, pues no era necesario hacer una reforma, ni pasar por conflictos sociales. Los territorios donde se debía cultivar eran baldíos (Carrión y Cuvi, 1985, p. 29), de ahí el enorme interés que suscitaba.

La estación Palma Africana en Santo Domingo se dedicó a la selección y mejoramientos de semillas. Las semillas fueron traídas a Ecuador de diferentes medios ecológicos para observar su adaptación a las condiciones nacionales, principalmente de Nigeria y Camerún, pero también de Colombia, una vez aquí fueron preseleccionadas en la plantación de Aceiteras Tropicales S. A. Para su cultivo se emplearon, entre otros, manuales procedentes del Instituto Nacional para el Estudio Agrario del Congo (INEAC). En 1972 se plantarán 15.00o ha dentro del marco de Adiestramiento en Preparación y Evaluación de Proyectos Agrícolas, un convenio con el BID y el Instituto Interamericano de Ciencias Agrícolas (IICA) de la Organización de Estados Americanos (oEA), que contó con el apoyo del Ministerio de Producción de Ecuador. 
El IRHO se ofrecerá para mejorar el material local y capacitar a los investigadores en sus estaciones en París y África. La entrega de semilla seleccionada desde 1966 (INIAP 1979, p. 76) y la organización de cursos de capacitación ayudará a su enorme crecimiento entre los años 1963-1978, pasando de 1300 a 25.000 ha de palma, de las que el $80 \%$ era material proveniente del INIAP (1979, p. 75).

La segunda reforma agraria de 1973 propiciada por los militares buscaba profundizar en la modernización por medio de iniciativas estatales y favorecer el desarrollo industrial (Verduga, 1977).La falta de aceites en el país justificaba políticamente el proyecto de palma africana (INIAP, 1979, p. 75). El Estado justificó la propagación de este cultivo por sus beneficios para el conjunto de la sociedad, en el sentido de creación de empleo rural, ahorro de divisas y abastecimiento de productos (Carrión y Cuvi, 1985, p. 32). Sin embargo, su cultivo fue básicamente para exportación en bruto, siendo su transformación en aceite relativamente reciente, desde hace tres décadas. En este periodo se abren las carreteras desde Santo Domingo a Quinindé, Quevedo (Carrión y Cuvi, 1985, p. 31) y Quito. La agricultura de la Costa en el triángulo Santo Domingo-Quevedo-Esmeraldas se va a orientar al cultivo de la palma, un cultivo orientado al mercado y asociado a un determinado modelo de producción y de acceso a tecnología (Carrión y Cuvi, 1985, p. 35).

Para que sea un cultivo exitoso, son necesarias como mínimo 40 ha, por tanto, se orientaba al agricultor mediano y grande. Su cultivo ocurrió de manera desigual, afectando a determinados productores, que fueron favorecidos por la política estatal gracias al acceso a créditos. La naturaleza del cultivo para la acumulación, junto a las condiciones de los mercados nacionales e internacionales, se materializó en el deseo de llevar los avances tecnológicos de la revolución verde (Carrión y Cuvi 1985, p. 13). Los años 70 están marcados por la presencia del sector privado y el aumento de la producción en determinados rubros, lo que favorece su investigación (Carrión y Cuvi, 1985, p. 14).

\section{PERÍODO DE GESTIÓN ESTATAL: 1979-1994}

En 1979, con la llegada de la democracia y el acceso a la presidencia del gobierno progresista de Jaime Roldós Aguilera, el INIAP pasará a ser gestionado por el Estado. Esto se tradujo en que los salarios de los técnicos bajaron, pues pasaron a ser considerados como burócratas. El presupuesto pasó de ser asignado por fundaciones privadas a ser gestionado por el Estado, lo que hizo menguar la financiación. El espacio social del INIAP está habitado por personas, y el espacio científico no es ajeno a las tomas posición y a las luchas de poder que ocurren en su seno. El acceso a títulos de PhD no solo establecía fronteras con los estudiantes de máster (Bourdieu, 1997, pp. 35-37), sino que favorecía el acceso a capital económico en la sociedad. Por lo que en esta segunda época, después de pagar sus becas, mucho del personal técnico que había accedido a títulos en universidades extranjeras se fue al sector privado o a otras instituciones públicas como el Banco de Fomento, lo que debilitó en gran medida al INIAP.

El marco conceptual en el que fueron formados muchos de los investigadores en el extranjero, bajo la óptica de la revolución verde, excluía a los agricultores a los que veían cómo marginales, resultado de una herencia que era preciso superar. La concepción de la investigación como algo sagrado que debía alcanzar la perfección, explicaría el que mucha de la investigación 
no fuese implementada en campo, pues consideraban que las variedades mejoradas no eran todo lo perfectas que debían ser, o que cuando se implementaron no fuesen adaptadas por los agricultores, pues el tipo de investigación desarrollada no consideraba necesario conocer las necesidades de los agricultores, que eran percibidos como meros receptores de variedades de semillas. Su papel se restringía a adaptar las variedades internacionales a las condiciones nacionales sin cuestionar.

Sin embargo, desde finales de los años 70, para que no fuese criticada la intervención internacional en el terreno político, ésta debía orientarse hacia el pequeño agricultor. Además, en el terreno internacional se era consciente de las limitaciones que implicaba el modelo de la revolución verde. Los modelos modernizadores serán cada vez más cuestionados desde los años 80 y la financiación internacional se orientará cada vez más a temas medioambientales. Las limitaciones de los modelos desarrollados por la revolución verde apuntaban hacia un enfoque más sostenible que permitiese corregir el reparto desigual de estas tecnologías (Wolf, 1986 , p. 6), que habían beneficiado mayormente a los grandes agricultores, dejando de lado a la cuarta parte de la población mundial (Wolf, 1986, p. 9). Estos cambios serán percibidos al interior del INIAP por los economistas agrarios, que serán el sector más innovador y su enfoque será considerado como heterodoxo por parte de los agrónomos, así como por la cooperación internacional que exigirá a los técnicos trabajar más de cerca con los pequeños agricultores. Estas pugnas ejemplifican luchas y tomas de posición durante décadas al interior del INIAP, todavía no resueltas.

DESARROLLO RURAL INTEGRADO Y PROGRAMAS DE INVESTIGACIÓN EN PRODUCCIÓN

Las intervenciones de la primera etapa orientadas a ayudar a los grandes agricultores fueron cuestionadas durante el periodo democrático. Desde mediados de los años 70 y comienzos de los 8o, la conflictividad campesina era muy fuerte, líderes como Lázaro Condo y Rafael Perugache fueron asesinados. Las sucesivas reformas no habían tenido el mismo efecto en todo el territorio nacional. En los años 80 las organizaciones de productores comenzaron de nuevo a organizarse para demandar tierra, esto llevó al gobierno a conceder créditos a las comunidades para comprar latifundios, lo que tuvo como resultado una mayor fragmentación de la tierra. La Secretaría de Desarrollo Rural Integrado (DRI) articulará las instituciones del Estado para promover un modelo rural que considere tanto aspectos productivos como de acceso a créditos, infraestructuras y servicios. Estos proyectos fueron promovidos por el Banco Mundial (BM) en un momento en que los pequeños agricultores comenzarán a cobrar mayor relevancia a nivel internacional. La Secretaría DRI fue implementada durante menos de cinco años, primero durante la presidencia de Jaime Roldós y, tras su muerte, por Oswaldo Hurtado.

El INIAP generaba tecnología para incrementar la producción basada en el criterio de los técnicos, pero sin considerar la demanda de los agricultores. Sin embargo, desde mediados de los años 70, la necesidad de abrirse a nuevos enfoques será señalada por el grupo de los economistas agrarios que comenzaron a trabajar con los técnicos agrícolas, produciendo una revisión del modelo de la revolución verde, aunque sin ser siempre escuchados ni entendidos. Esto generó luchas de posicionamiento al interior del INIAP, los ingenieros agrónomos se sintieron cuestionados por los economistas que proponían modelos estadísticos donde la 
productividad estaba influida por diversos aspectos sociales, climáticos y biofísicos. Sus trabajos en los Programas de Investigación en Producción (PIP), centrados en la extensión agraria a través de la investigación, actuaron como un enlace entre la investigación y la transferencia. Los PIP funcionaron desde finales de los años 70 hasta mediados de los 80 - se centraron en cereales y fueron apoyados por el сіммүт—, visibilizando la gran cantidad de aspectos que era preciso considerar para desarrollar un modelo agrario que pudiese responder a las necesidades nacionales. Pues aunque los pequeños agricultores habían accedido a tierra, carecían de créditos. Después los PIP dieron paso a los programas de transferencia y validación de tecnología, que más tarde se reducirían solo a la validación de tecnología.

\section{CULTIVOS ANDINOS}

El Centro de Investigación para el Desarrollo Internacional canadiense, IDRC por sus siglas en inglés, se mostró interesado desde los años 80 en proyectos agrarios más integrales centrados en cultivos que permitiesen mejorar las condiciones de vida de los agricultores andinos. En la investigación y selección de semillas de granos y tubérculos andinos tenía un peso mayor la participación de los agricultores, puesto que los centros internacionales carecían de estas semillas. La investigación acción participativa considera que los agricultores deben ser desde el inicio partícipes en el proceso, y sus necesidades deben ser consideradas e integradas en la investigación. Aunque estos enfoques se instauraron en el país a partir de 1995, en el programa de cultivos andinos ya eran utilizados desde los años 8o. Estos proyectos permitieron que se recuperasen variedades nativas promoviendo su cultivo en campo y generando un banco de germoplasma. En los años 9o, el proyecto para el fortalecimiento de la papa en la Sierra (FORTIPAPA) financiado por la Cooperación Suiza de Desarrollo (COSUDE), también puso como condición necesaria para que se recibiese financiación la colaboración de los agricultores mediante la organización de cooperativas agrarias.

\section{LA DEUDA Y LA CRISIS AGRARIA}

Desde finales de los años 60, el petróleo guiará el desarrollo del país. A partir de 1972, las exportaciones de petróleo hicieron crecer la economía al 6,15\% anual, lo que se mantuvo hasta 1984, situando a Ecuador entre los países con la tasa de crecimiento más alta de América Latina (Jordán 1988, pp. 15-16). A finales de los años 80, el sector agrícola seguía siendo el principal, por delante del sector industrial y el petrolero (Janvry y Glikman, 1991, pp. 14-15). Sin embargo, entre 1965-1971 solo creció el 1,72 \% anual y su participación en el PIB pasó del 25,8 \% en 1965 al 13,4 \% en 1984 (Jordán, 1988, pp. 15-16). A partir de 1975 aumentó enormemente la deuda, resultado de una fuerte política de endeudamiento favorecida por los préstamos de bancos internacionales. En la década de los 8o, la deuda externa del país aumentó, pasando de 4652 millones de dólares en 1980 a 6690 de dólares 1983. El peso de la deuda externa privada era superior al de la pública: 29,4\% y 25,1 \% respectivamente. Esto explicaría las medidas adoptadas por el gobierno de Hurtado, que provocaron cuatro huelgas generales (Cueva, 2003, p. 93). Aunque el Estado siempre fuese débil, su papel fue aún menos predominante desde 1980, momento en el que prácticamente fue reemplazado por las organizaciones no gubernamentales (ONG), que comenzaron a dictar las políticas del desarrollo rural. Esto contrasta con la 
posición predominante que mantuvo el Estado en las décadas de 1960 y 1970, y que se materializó en la reforma agraria (Bretón, 2008, pp. 584-585).

El gobierno de Febres Cordero impulsará desde 1984 políticas de ajuste y de libre mercado (Janvry y Glikman, 1991, p. 14), y concederá mayor espacio al sector agrario privado. Entre las décadas de 1980 y 1990 hubo una enorme proliferación de proyectos de desarrollo rural (Bretón, 2008, p. 583). Esta época de ONG duró toda la década de los años 9o, incluso hasta el siglo XXI. En la década de 1990, el INIAP no cierra gracias a la financiación recibida desde la cooperación internacional, pues la erosión del Estado por las políticas de ajuste estructural impregnadas de una filosofía antiestatal fruto del Consenso de Washington (Bretón, 2008, p. 584) fue enorme.

\section{CONCLUSIONES DESDE UNA MIRADA ACTUAL}

El modelo agrario que se expande a través de la revolución verde basado en la agricultura estacional desarrollada en las llanuras del centro de Estados Unidos contó con el apoyo económico de un Estado fuerte capaz de articular la investigación, la extensión y la educación universitaria. Sin embargo no era el más adecuado para la realidad de los trópicos. La inexistencia de un Estado fuerte por la herencia colonial y la falta de comunicación entre la extensión, la investigación y la universidad, junto con la incapacidad inherente de estos modelos para entender las particularidades locales, ha impedido que este modelo haya sido realmente exitoso. La exportación de productos para la guerra y para el comercio internacional fue una tendencia que marcó la especialización nacional en productos agrícolas primarios, y no se profundizó en su transformación hasta hace tres décadas, por lo que la agro industria nacional es incipiente.

La investigación agraria ha sido dependiente de la financiación externa, al ser el Estado ecuatoriano excesivamente débil. Esto hizo que el INIAP dependiese de fondos provenientes de la cooperación internacional, lo que de algún modo impidió su emancipación y favoreció el desarrollo de unas áreas en detrimento de otras. En el Ministerio de Agricultura, Ganadería, Acuicultura y Pesca (MAGAP) los presupuestos siempre fueron reducidos, lo que unido a la falta de continuidad en la políticas agrarias, por los excesivos cambios de gobierno y por los constantes cambios de ministros de agricultura impidieron el desarrollo de una política de Estado para la agricultura. La inversión se centró en determinados sectores que permitían modernizar el sector agrario sin que se afectase al corazón de la propiedad de la tierra, y no se generaron tecnologías adaptadas a las necesidades de los pequeños agricultores para paliar este desajuste.

En la década de 1970 se generaron varios sectores agrícolas fuertes en el sector privado por la captación del personal técnico formado durante la primera época del INIAP, especialmente en los sectores lechero y en el de la palma, que fueron acaparados por los grupos que tenían mayor acceso a tierra. La convergencia entre el capital económico, cultural -científico- y político durante el proceso modernizador en el periodo previo a la democracia, se tradujo en una toma de posición estratégica por parte del sector privado, que acaparó bienes y servicios públicos mediante la acumulación de capital político (Bourdieu, 1997, p. 30). Por tanto, en la primera época se produjo la orientación de un Estado débil e incipiente hacia los intereses de los grandes propietarios, así como un trasvase progresivo del personal formado en el INIAP hacia la empresa privada, que será la que indirectamente se beneficie en 
mayor medida de la financiación internacional al apropiarse del personal y de una tecnología adaptada a sus necesidades.

Esta confluencia se observa en el cultivo de palma y en la ganadería lechera, estabilizando dos espacios estratégicos en el panorama nacional como son la Sierra y la Costa. La convergencia del capital económico y el cultural producen un efecto beneficioso para los sectores con mayor acceso a capital económico. En este proceso, los investigadores logran posicionarse en la sociedad ecuatoriana gracias a su acceso al conocimiento científico, que representa un nuevo capital escaso hasta ese momento en el país. La acumulación de capital económico y tecnológico por parte del sector privado le permite salir muy fortalecido del proceso modernizador, lo que facilitará su despegue tecnológico futuro. Se podría decir que el trabajo del INIAP fue fagocitado por estos sectores, que ya eran históricamente fuertes y supieron adaptarse a los nuevos tiempos. En la Sierra, los hacendados más innovadores se modernizaron transformándose en productores lecheros, suministrando productos a las urbes crecientes. Sin embargo, los efectos de la modernización agraria apenas se van a sentir en los pequeños agricultores, que van a pasar totalmente desapercibidos a este efecto.

En el INIAP, el modelo de financiación fragmentado dio lugar a un modelo de investigación parcelado donde no todos los rubros se desarrollaron de la misma manera, pues el acceso a recursos financieros dependía de los intereses de la cooperación internacional, lo que impidió que el INIAP funcionase como un organismo autónomo, generando atrofias y desarrollos asimétricos. La investigación estuvo marcada por las prioridades de los donantes y no por las necesidades nacionales, y aunque esto fue una constante desde su fundación en el periodo de los años 90 alcanzó un cariz dramático. El iniap se basó en la oferta de tecnología, pero sin considerar la demanda ni la heterogeneidad del agro ecuatoriano. Las variedades ofertadas eran muy exigentes a nivel económico en fertilización y control sanitario. Las necesidades de los pequeños agricultores son diferentes a las de los grandes, por tanto, el tipo de tecnología por adaptar debería de haber sido diferente a nivel de costo, complejidad y acceso. Si bien a comienzos de los años 80 estos aspectos comenzaron a cobrar relevancia en ciertos cultivos como la papa y los cultivos andinos, en términos generales éste no fue el caso.

Esto ha significado que el impacto del proceso modernizador no haya sido homogéneo. Aunque es cierto que ha habido proyectos que pueden ser considerados como exitosos, en términos generales el instituto no ha sido capaz de entender la realidad agraria del país, una constante que ha ido arrastrando y de la que difícilmente se puede librar sin que haya un proceso de renovación profundo. Se han generado espacios de investigación estancos y aislados, que no han sido capaces de articularse de modo transversal, esto hubiese sido responsabilidad del Estado, pero éste era demasiado débil, su aparato fue utilizado con otros fines, y los «problemas» eran otros.

Las diferentes reformas agrarias no terminaron de integrar realmente a los pequeños productores, que accedieron a pequeños terrenos, pero carecían de los elementos necesarios como crédito, educación y riego. Además, este proceso ha resultado en una excesiva fragmentación de la tierra en las zonas marginales, asociadas a una baja productividad. Los técnicos ecuatorianos que regresaban con su formación de Estados Unidos solo podían ser útiles para implementar un modelo agrario viable para las grandes propiedades, y aquellos más abiertos a trabajar con los pequeños debieron de vencer oposiciones constantes. Esto se tradujo en un 
desencuentro entre la realidad nacional y el modelo conceptual bajo el que fueron formados. Las investigaciones se centraron en el manejo de los cultivos desde la siembra a la cosecha. Esta ausencia en el manejo poscosecha hizo que nunca se trabajasen realmente temas relacionados con la comercialización, ni se identificasen nichos de mercado potenciales. Además, la extensión no ha hecho debidamente su trabajo, lo que ha resultado en una baja adopción de tecnologías entre los pequeños y en la baja calidad de los productos.

Por otro lado, el enfoque de investigación heredero de la revolución verde ha obviado en gran medida a las personas, que fueron suprimidas de los procesos agrarios. Las investigaciones, salvo honrosas excepciones, motivadas por los deseos de los financiadores y el arduo trabajo de los investigadores, se han centrado en aspectos técnicos. De hecho, si se revisan los informes técnicos del INIAP, en las primeras décadas el ser humano prácticamente no aparece. El INIAP no se adaptó a los nuevos tiempos, mientras en la esfera internacional se producían cambios en los enfoques agrarios, los aspectos medioambientales cobraban una mayor relevancia y se trabajaba con tecnologías adaptadas al pequeño agricultor, el INIAP ha permanecido prácticamente impermeable a estos cambios, y aquellos que han podido liderar una renovación de la institución fueron progresivamente abandonándola, al experimentar una enorme dificultad para que sus demandas fueran escuchadas. Además, los bajos salarios remunerados al personal investigador del INIAP, con respecto a otros sectores que demandaban profesionales con el mismo perfil, han favorecido el abandono de la institución. El hecho de que la política al interior de la institución impidiese en gran medida el ascenso social si no era por la vía administrativa hizo que se desperdiciara la formación de muchos investigadores, que fueron desplazados a tareas administrativas al regresar de su formación con el $\mathrm{PhD}$.

Desde mediados de los años 80 hasta finales de los años 90 se impondrá la lógica de lo privado frente a lo público, que llevará a la institución a una situación de extrema debilidad. Sin embargo, la sólida formación adquirida durante sus inicios gracias a la visión del ingeniero Fabián Portilla, que supo posicionar al INIAP en la esfera internacional, y el compromiso de los investigadores por impedir su disolución, permitirá al INIAP mantenerse en el tiempo.

\section{REFERENCIAS}

Akraam-Lodhi, H. y Kay, C. (enero, 2010). Surveying the agrarian question (part 1): unearthing foundations, exploring diversity. Journal of Peasant Studies, 37(1), 177-202.

Altieri, M. y Nicholls C. (segundo semestre, 2010). Agroecología: potenciando la agricultura campesina para revertir el hambre y la inseguridad alimentaria en el mundo. Revista de Economía Crítica, (10), 62-74.

Arce, A. y Long, N. (1992). The dynamics of knowledge Interfaces between bureaucrats and peasants. En $\mathrm{N}$. Long (Ed.), Battlefields of knowledge: the interlocking of theory and practice in social research and development (pp. 211-246). New York, UsA: Routledge.

Barsky, O. (1988). La Reforma Agraria ecuatoriana. Quito, Ecuador: Corporación Editora Nacional/ FLACSO-Ecuador.

Borlaug, N. (2000, septiembre). The Green Revolution Revisited and The Road Ahead, Ponencia presentada en Special $30^{\text {th }}$ Anniversary Lecture in The Norwegian Nobel Institute. Oslo, Noruega.

Bourdieu, P. (1997). Razones prácticas sobre la teoría de la acción. Barcelona, España: Editorial Anagrama. 
Bretón, V. (octubre, 2008). From Agrarian Reform to Ethnodevelopment in the Highlands of Ecuador. Journal of Agrarian Change, 8(4), 583-617.

Bruun, H. y Hukkinen, J. (2013). Cruzando fronteras: un diálogo entre tres formas de comprender el cambio tecnológico. En H. Thomas y A. Buch (Eds.), Actos, actores y artefactos: sociología de la tecnología (pp. 185-216). Buenos Aires, Argentina: Bernal, Universidad Nacional de Quilmes.

Callon, M. (2013). La dinámica de las redes tecnoeconómicas. En H. Thomas y A. Buch (Eds.), Actos, actores y artefactos: sociología de la tecnología (pp. 47-184). Buenos Aires, Argentina: Bernal, Universidad Nacional de Quilmes.

Carrión, L. y Cuvi, M. (1985). La palma africana en el Ecuador: Tecnología y expansión empresarial. Quito, Ecuador: FLACSO.

Cosse, G. (1980). Reflexiones acerca del Estado, el proceso político y la política agraria en el caso ecuatoriano 1964-1977. En O. Barsky (Ed.), Ecuador: Cambios en el agro serrano (pp. 389-436). Quito, Ecuador: CEPLAES.

Cueva, A. (2003). El proceso de dominación política en el Ecuador. Quito, Ecuador: Editorial Planeta.

Edwin T. Layton, Jr. (1987). European origins of the American engineering style of the nineteenth century. En N. Reingold y M. Rothenberg (Ed.), Scientific Colonialism: a cross - cultural comparison (pp. 151-166). Washington D.C., UsA: Smithsonian Institution Press.

Escobar, A. (2007). La invención del Tercer Mundo: construcción y deconstrucción del desarrollo. Barcelona, España: Editorial Norma.

Hughes, T. P. (2013). La evolución de los grandes sistemas tecnológicos. En H. Thomas y A. Buch (Eds.), Actos, actores y artefactos: sociología de la tecnología (pp. 101-146). Buenos Aires, Argentina: Bernal, Universidad Nacional de Quilmes.

INIAP (1979). 17 años al servicio del agro ecuatoriano 1962-1979. Quito, Ecuador: INIAP.

INIAP (1970-1975). Convenios. Departamento de Administración noviembre-diciembre 1975. Quito, Ecuador. INIAP (1971-1975). Archivos del Departamento de Administración de Santo Domingo-Palma Africana. Quito, Ecuador.

Janvry, A. y Glickman, P. (1991). Encadenamientos de producción en la economía campesina en el Ecuador. San José, Costa Rica: FIDA y IICA.

Jordán, F. (1988). El minifundio: su evolución en el Ecuador. Quito: Corporación Editora Nacional.

Kay, C. (2008). Reflections on Latin-American Rural Studies in the Neoliberal Globalization Period: a New Rurality? Development and Change, 39(6), 915-943.

Kloppenburg, J. R. (1988). First the Seed: The Political Economy of Plant Biotechnology, 1492-20oo. Cambridge, uk: Cambridge University Press.

Latour, B. (2007). Nunca fuimos modernos: ensayo de antropología simétrica. Buenos Aires, Argentina: Siglo xxi Editores, Argentina.

Latour, B. (2005). Introducción: cómo retomar la tarea de rastrear asociaciones e Introducción a la parte I: del buen uso de las controversias. En B. Latour (Ed.), Reensamblar lo social: una introducción a la teoría del actor-red (pp. 13-45). Buenos Aires, Argentina: Ediciones Manantial.

Latour, B. (1992). Ciencia en acción. Barcelona, España: Editorial Labor S. A.

Leys, C. (1996). The rise \& fall of development theory. Oxford, UK: EAEP.

Martínez, L. (1983). Capitalismo agrario: crisis e impacto social. En J. Moncada (Ed.), Ecuador: presente y futuro (pp. 37-84).Quito, Ecuador: Editorial El Conejo. 
McMichael, P. (200o). Global food politics. En F. Magdoff, J. Bellamy Foster y F. H. Buttel (Eds.), Hungry for profit: agrobussiness: the agribusiness threat to farmers, food, and the environment (pp. 125143). New York, usa: Monthly Review Press.

Moore, J. W. (July, 2010). The end of the road? Agricultural Revolutions in the Capitalism World-Ecology 1450-2010. Journal of Agrarian Change, 10(3), 389-413.

Murmis, M. (1980). El agro serrano y la vía prusiana de desarrollo capitalista. En O. Barsky (Ed.), Ecuador: cambios en el agro serrano (pp. 8-50). Quito, Ecuador: CEPLAES.

Ortega Aranda, E. L. (1966). La Carta de Punta del Este y la Alianza Para el Progreso. Facultad de Ciencias Jurídicas y Sociales Universidad de Chile, Seminario de Derecho Público N. ${ }^{2}$ 21. Santiago de Chile, Chile: Editorial Jurídica de Chile.

Parayil, G. (2003). Mapping technological trajectories of the Green Revolution and the Gene Revolution from modernization to globalization. Research Policy, (32), 971-990.

Pinch, T. J. y Bijker, W. E. (2013). La construcción social de hechos y de artefactos. En H. Thomas y A. Buch (Eds.), Actos, actores y artefactos: sociología de la tecnología (pp. 19-62). Buenos Aires, Argentina: Bernal, Universidad Nacional de Quilmes.

Pinch, T. J., Ashmore, M., Mulkay, M. (1992). Tecnology Testing, Tex: Clinical Budgeting in the UK National Health Service. En J. Law y W. E. Bijker (Eds.), Shaping technology/ building society: studies in sociotechnical change (pp. 265-289). Massachusetts, USA: Massachusetts Institute of Technology.

Robles, J. V. (2011). Memorias de 50 años de vida del Instituto Nacional Autónomo de Investigaciones Agropecuarias-InIAP. Guayaquil, Ecuador: INIAP.

Rostow, W. W. (1961). Las etapas del crecimiento económico. Un manifiesto no comunista. México DF, México: Fondo Cultura Económica.

Scott, J. C. (1998). Seeing Like a State. How Certain Schemes to Improve the Human Conditions have Failed. New Haven y Londres, UK: Yale University Press.

Silver, B. (2005). Fuerzas de trabajo: los movimientos obreros y la globalización desde 1970. Madrid, España: Akal.

Stewart, R. (1986). The Social Construction of Artefacts: A Response to Pinch and Bijker. Social Studies of Science, 16(2), 331-346.

Sweezy, P. (1972). Crítica a la ciencia económica. Buenos Aires, Argentina: Periferia s. R. L.

Verduga, C. (1977). Política económica y desarrollo capitalista en el Ecuador contemporáneo: una interpretación. Quito, Ecuador: Editorial Bolívar.

Wolf, E. C. (1986). Beyond the Green Revolution: New Approaches for ThirdWorld Agriculture. Worldwatch Paper, (73). Washington D. C., UsA: Worldwatch Institute. 
